๑ Entomologica Fennica. 29 December 2003

\title{
Review of the genus Baeosciara Tuomikoski (Diptera: Sciaridae)
}

\author{
Pekka Vilkamaa
}

\begin{abstract}
Vilkamaa, P. 2003: Review of the genus Baeosciara Tuomikoski (Diptera: Sciaridae). - Entomol. Fennica 14: 220-226.

The genus Baeosciara Tuomikoski, 1960, Holarctic in distribution, includes the following species: B. discolor (Lengersdorf) (Europe), B. scotica (Edwards) (Europe, northern North America), B. sinuata (Menzel \& Mohrig) (Europe) and $B$. pectinata sp. n. (western Canada). The new species is described, the other species are redescribed or diagnosed. Based on my earlier cladistic analysis of the Trichosia group of genera, the original generic rank of Baeosciara is restored.
\end{abstract}

Pekka Vilkamaa, Finnish Museum of Natural History, Zoological Museum, P.O. Box 17, FIN-00014 University of Helsinki, Finland; E-mail: pekka.vilkamaa@helsinki.fi

Received 26 March 2003, accepted 05 September 2003

\section{Introduction}

Menzel and Mohrig $(1997,2000)$ proposed a new classification of Trichosia Winnertz (type-species Trichosia splendens Winnertz) and related groups, including Baeosciara Tuomikoski (Leptosciara pusillima Frey) and Mouffetina Frey (Plastosciara pulchricornis Edwards) as subgenera of Trichosia. They based the monophyly of their Trichosia ( $s$. l.) on the conical, elongated tegmen with oblique apex. The structure of the tegmen is variable even within Baeosciara, and the proposed classification was challenged by my cladistic analysis based on 70 morphological characters on adult males (primary data for Vilkamaa [2003]). According to the analysis neither Baeosciara nor Mouffetina could be classified as subgenera of Trichosia as they were placed in a different clade, Baeosciara as the sister group of a large clade including Lestremioides Frey + Mouffetina as the sister group of Scythropochroa Enderlein, Schwenckfeldina Frey and Chaetosciara Frey. Although even this result was not very well supported (by three character state changes) it was based on a strict cladistic analysis and I regard it as a more reliable hypothesis on the phylogeny of the groups in question. Based on this hypothesis I use here Baeosciara in its original generic rank. The main aim here is to diagnose the genus and the species included now that more material is available, redefining previous descriptions (Tuomikoski 1960, Menzel \& Mohrig 1997, 2000), The three earlier known species are diagnosed or redescribed and a new species, found in British Columbia, Canada, is described. The new material shows that the genus has a Holarctic distribution.

\section{Material and methods}

For the taxonomic treatment, the specimens were mounted on microscope slides in Euparal, after dehydrating them in absolute ethanol. The morphological terminology follows that used by Hippa and Vilkamaa (1991). The taxonomic study is based on the males only. The material of Baeosciara studied is deposited in Zoological Museum, Finnish Museum of Natural History, Helsinki (MZH), Canadian Na- 
tional Insect Collection, Ottawa (CNC), Deutsches Entomologisches Institut, Eberswalde (DEI), Zoologisches Forschungsinstitut und Museum Alexander Koenig, Bonn (ZFMK), Swedish Museum of Natural History, Stockholm (NRM) and in the Private Collection of Kai Heller (PKHK).

\section{The genus Baeosciara Tuomikoski, 1960}

\section{1. Description of male}

Small or medium-sized Sciaridae, wing length $1.6-2.8 \mathrm{~mm}$.

Head dark brown. Interfacetal hairs long, extending well over the surface of facets. Eye bridge complete, with 3-4 rows of facets. Anterior vertex bare. Prefrons with numerous setae. Clypeus non-setose or with 1 seta. Proboscis normal. Maxillary palp 3-segmented, segments short or normal (B. scotica); segment 1 with 2-7 setae, with the sensillae scattered on dorsal surface. Antennal flagellum short, length/width of flagellomere 4 1.10-1.75. Flagellomeres with distinct apical margins, with rather smooth surface, with setae shorter than diameter of segment, with short necks.

Thorax dark brown. Notal setae dark $(B$. discolor and B. pectinata) or pale (B. scotica and $B$. sinuata). Acrostichal setae extending from anterior to posterior part of scutum, dorsocentral and supra-alar and scutellar setae with mixed strong and weak ones. Episternum 1 with 4-13 setae. Posterior pronotum setose, mediotergite and mesoanepisternum nonsetose. Mesokatepisternum high and subtriangular.

Wing fumose brown. Wing length 1.6-2.8 $\mathrm{mm}$, anal lobe moderately developed. Wing veins normal. Wing membrane nonsetose, veins $\mathrm{M}$ and $\mathrm{Cu}$ dorsally setose, hind margin of wing dorsally and ventrally setose. Halter normal, with many rows of dorsal setae.

Legs pale. Legs normal, length of front basitarsomere/length of front tibia 0.45-0.60.

Tibiae with moderately strong spinose setae, modified subapical anteroapical setae of front tibia in patch, not in depression. Tibial spurs 1:2:2, spurs longer than apical width of tibia. Tarsal claws without teeth.

Abdomen dark, normal. Hypopygium without intercoxal lobe. Gonocoxite moderately ( $B$. discolor and B. pectinata) or slightly (B. scotica and $B$. sinuata) elongated, with one elongated seta at ventroapical corner. Gonostylus elongate, with group of megasetae on medial-subbasal mesial lobe, $B$. discolor and $B$. pectinata in addition with scattered megasetae on whole mesial side of gonostylus; B. scotica with some short stout subapical megasetae; gonostylus with 1-5 mesial whiplash-like narrow elongated setae (lacking in $B$. scotica); without apical tooth (present in $B$. sinuata). Tegmen of various form, with sclerotized parameres, apically membraneous (except $B$. sinuata in which tegmen membraneous, apart from laterally strongly sclerotized aedeagal plate). Genital rod well sclerotized. Tergites 9 and 10 normal, sternite 10 with 1-2 setae on each half.

\section{2. Diagnostic characters}

The species of Baeosciara resemble the species of other groups traditionally placed near Trichosia (Trichosia (s. s.) Lestremioides Frey, Mouffetina, Scythropochroa, Chaetosciara) which have at least one of the following characters: setose posterior pronotum, setose hind veins of wing and dorsally and ventrally setose hind margin of the wing, sensillae of the first segment of maxillary palp scattered or in indistinct patch on its dorsal surface, the front tibial apex with an anteroapical subapical patch of setae not bordered basally nor distinctly depressed, and in not having an apical tooth, except in one species. Baeosciara is similar to Trichosia and Schwenckfeldina in having mesial megasetae on the gonostylus. Baeosciara differs from Trichosia (s. s.) and is similar to Lestremioides, Mouffetina, Scythropochroa, Schwenckfeldina and Chaetosciara in having subapical-apical group of megasetae (except $B$. sinuata) and in having elongated whiplash-like setae mesially on the gonostylus (the latter character state lacking in B. scotica). Baeosciara is distinguished from all above-mentioned groups in having a very short antennal flagellum and maxillary palp and in having a subbasal lobe with megasetae on the gonostylus. Schwenckfeldina also has a megasetae-bearing lobe on the gonostylus and a short antennal flagellum but its gonostylar lobe is medial, not subbasal, it has a longer maxillary palp with a distinct sensory pit, non-setose hind veins of wing and only the dorsal row of setae on the hind margin of wing. 



Fig. 1. Part of hypopygium (A, C) and gonostylus (B, D), ventral view. - A-B. Baeosciara discolor (Lengersdorf) (from Karelia). - C-D. B. pectinata sp. n. (holotype). Scale $0.10 \mathrm{~mm}$. 1 = gonostylus, 2 = gonostylar megaseta, 3 = elongated seta, 4 = gonocoxite, 5 = tegmen .

\section{3. Key to the species of Baeosciara}

The characters are from a ventral view.

Mesial side of gonostylus impressed, with stout megasetae throughout subbasal-apical part, tegmen laterally angular (Fig. 1)
- Mesial side of gonostylus not impressed, with megasetae only on subbasal lobe or in addition with a few short megasetae subapically, tegmen not angular (Fig. 2) ..... 2 Gonostylus without subapical megasetae, its subbasal lobe with 15-20 megasetae, its mesial side with five whiplash-like elongated setae, apical tooth present (Fig. $2 \mathrm{~A}, \mathrm{~B})$ B. sinuata (Menzel \& Mohrig) 

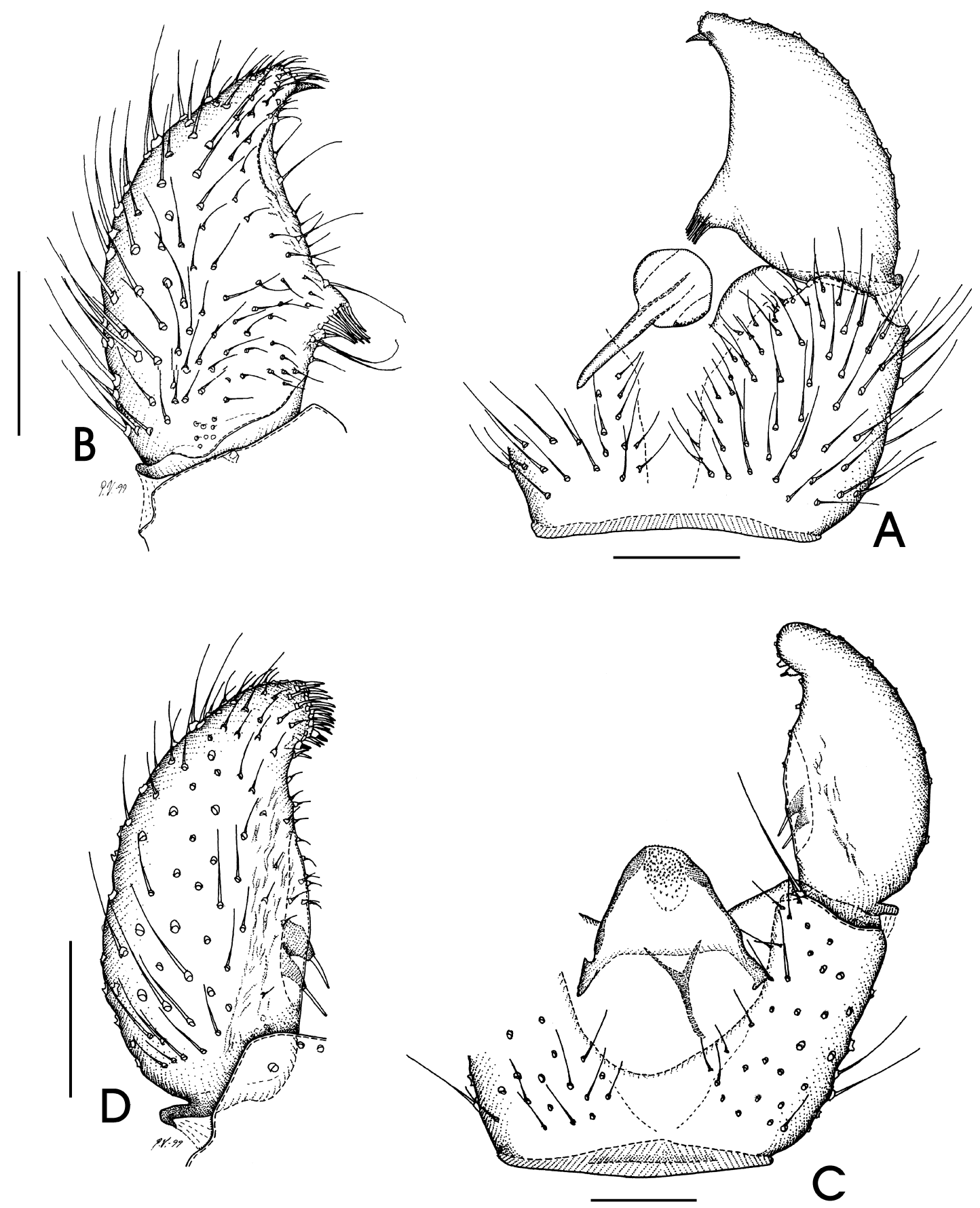

Fig. 2. Part of hypopygium (A, C) and gonostylus (B, D), ventral view. - A-B. Baeosciara sinuata (Menzel \& Mohrig) (from Finland). - C-D. B. scotica (Edwards) (from Finland). Scale $0.10 \mathrm{~mm}$.

- Gonostylus with some short stout subapical megasetae, its subbasal lobe with 2 or 3 megasetae, its mesial side with numerous subequal short setae, without whiplashlike elongated setae, apical tooth absent (Fig. 2C, D)
B. scotica (Edwards) Subbasal mesial megasetae in group on low basal plate, one whiplash-like seta on apical half-apical third of gonostylus, tegmen broad and laterally smoothly 
angular (Fig. 1A, B) .......... B. discolor (Lengersdorf)

- Subbasal mesial megasetae in row on distinct lobe, one whiplash-like seta on apical fourth of gonostylus, tegmen high and laterally sharply angular (Fig. 1C, D) B. pectinata sp. n.

\section{Baeosciara discolor (Lengersdorf, 1928) comb.} n. (Fig. 1)

\section{Sciara discolor Lengersdorf, 1928:18.}

Leptosciara pusillima Frey, 1948:28. syn.

Baeosciara pusillima Tuomikoski, 1960

Trichosia (Baeosciara) discolor, Menzel \& Mohrig 1997

Material examined. Holotype female: GERMANY, Hinterstein in Allgäu, August, Lengersdorf (ZFMK). Other material. GERMANY, Oberbayern, Grainau, SW of GarmischPartenkirchen, Obergrainau, Höhenrain, Panoramaweg, $47^{\circ} 28^{\prime} 47^{\prime \prime} \mathrm{N} 11^{\circ} 01^{\prime} 10^{\prime \prime} \mathrm{E}, 800$ $830 \mathrm{~m}$ a.s.l., spruce forest, sweep-net, 15.VI.2002, F. Menzel, 1 ○’ (DEI), FINLAND, N: Löparö, 7.VII.1940, R. Frey (holotype of Leptosciara pusillima Frey), Kn: Kuhmo, Sivakka (709:63), 8.VIII.1986, J. Tuiskunen, 1 ơ (MZH), Sb: Kangaslampi, Malaise trap, 6.-7.VII.1999, N. Laurenne, $10^{7}$ (MZH), Ta: Somero, Koisthuhta, 26.-27.VII.1986, H. Hippa, 1 ơ $^{7}(\mathrm{MZH}), \mathrm{Ab}$ : Vihti, Vihtijärvi, VII.1959, R. Tuomikoski, 1 O" (MZH), same data but 20.VI.1960, 1 \& (MZH), RUSSIA, Karelia, Kivach, 8.-10.VII.1985, Yakovlev, $1 \mathrm{O}^{7}(\mathrm{MZH})$, same data but pine forest, 5.-7.VIII.1986, 1 O' $^{7}$ (MZH).

Description of male. Head. Eye bridge with 3-4 rows of facets. Prefrons with 14-19 setae. Antennal flagellum short, flagellomeres with short pale setosity, with short necks, length/width of flagellomere 4 1.10-1.35. Maxillary palp short, with three segments, segment 1 with 2 setae, sensillae scattered on dorsal side.

Thorax darkish brown. Episternum 1 with 46 setae. Dorsal margin of katepisternum slightly angulate. Pleural pit just at anterior part of margin.

Wing hyalinous. Length $1.6-1.7 \mathrm{~mm}$. Anal lobe well developed. c/w 0.70-0.85, R1/R 0.70.1.05. bM nonsetose or with some dorsal setae, $\mathrm{r}$ m, stM, M1, M2, Cu1 and Cu2 with dorsal setae. Hind margin with dorsal and ventral setae.

Legs pale brown. Front tibia with some ventral and posterodorsal spinose setae. Length of front basitarsomere/length of front tibia 0.45-0.50. Front tibia subapically with anteroapical patch of setae.

Abdomen pale brown. Hypopygium (Fig. 1A, B). Sternite 9 with 1 (rarely 2) seta in each half.

Female. See Menzel and Mohrig (1997).

Discussion. Menzel and Mohrig (1997) synonymized Baeosciara pusillima (Frey) with $B$. discolor (Lengersdorf), the type material of which consists of one female only. For further discussion, see under $B$. pectinata.

\section{Baeosciara pectinata sp. n. (Fig. 1C, D)}

Material examined. Holotype male: CANADA, British Columbia, Vancouver Island, Upper Carmanah Valley, forest floor, malaise trap, 30.VII.1991, N. Winchester (CNC). Paratypes: same data as holotype, $1 \mathrm{O}^{7}(\mathrm{MZH})$, same locality but forest canopy, malaise trap, 15.VII.1991, N. Winchester, $10^{7}$ (CNC).

Description of male. Head. Eye bridge with 4 rows of facets. Prefrons with 5-7 setae. Antennal flagellum short, flagellomeres with short pale setosity, with short necks, length/width of flagellomere 4 1.55-1.75. Maxillary palp with three segments, segment 1 with 2-3 setae, sensillae scattered on dorsal side.

Thorax darkish brown. Episternum 1 with 610 setae. Dorsal margin of katepisternum slightly angulate. Pleural pit just at anterior part of margin.

Wing hyalinous. Length $1.9 \mathrm{~mm}$. Anal lobe well developed. c/w 0.65-0.80, R1/R 0.95-1.05. bM nonsetose or with 1 dorsal seta, r-m, stM, M1, $\mathrm{M} 2, \mathrm{Cu} 1$ and $\mathrm{Cu} 2$ with dorsal setae. Hind margin with dorsal and ventral setae.

Legs pale brown. Front tibia with some ventral and posterodorsal spinose setae. Length of front basitarsomere/length of front tibia 0.50. Front tibia subapically with anteroapical patch of setae.

Abdomen pale brown. Hypopygium (Fig. 1C, D). Sternite10 with 1-2 setae on each half.

Female. Unknown.

Etymology. The specific name refers to the comb-like row of the megasetae on the gonostylus.

Discussion. Baeosciara pectinata is similar to $B$. discolor and different from B. scotica and $B$. 
sinuata in having stout megasetae on the apical half of the gonostylus, in having an angular tegmen, and in being distinctly smaller. Baeosciara pectinata differs from $B$. discolor e.g. by having the subbasal megasetae of its gonostylus longer and in a row on a distict lobe, by having the mesial whiplash-like seta more apically on the gonostylus and by having its aedeagus higher and with more acuminate lateral shoulders (Fig. 1).

Baeosciara scotica (Edwards) comb. n. (Fig. 2C, D)

Sciara scotica Edwards, 1925:536.

Trichosia scotica, Tuomikoski, 1960

Trichosia (Baeosciara) scotica, Menzel \& Mohrig, 1997

Material examined. FINLAND, Ks: Kuusamo, Juuma, 3.VII.1958, R. Tuomikoski, 1 O' (MZH), Ks: Kuusamo, Kiutaköngäs, 1.VII.1958, R. Tuomikoski, 1 O' (MZH), Lk: Rovaniemi, Pisavaara, 30.VI.1964, R. Tuomikoski, 1 0" (MZH), same data but 13.VII.1965, 6 o' (MZH), N: Espoo, Westend, 8.VII.1962, W. Hackman, 1 $\sigma^{7} \quad(\mathrm{MZH}), \quad$ GERMANY, Thuringen, Friedrichroda, beech forest, Heller, $10^{7}$ (PKHK),

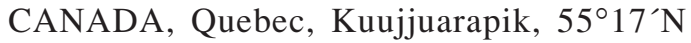
$77^{\circ} 48^{\prime} \mathrm{W}$, forest fire site, yellow trap, 14.VII.1.VIII.1990, S. Koponen, $10^{7}$ (NRM), same data but 1.-19.VIII.1990, $10^{7}$ (NRM), same data but 7.-10.VIII.1990, 1 o' (NRM), USA, Alaska, 11 mi S Anderson Jct., Rte 3, mi 270, alder-poplarspruce, malaise trap, 23.VI.-2.VIII.1984, S. \& J. Peck, $10^{7}$ (MZH).

Description of male. Head. Eye bridge with 3-4 rows of facets. Prefrons with 6-16 setae, clypeus non-setose or with 1 seta. Antennal flagellum short, flagellomeres with short pale setosity, with short necks, length/width of flagellomere 4 1.50-1.75. Maxillary palp with three segments, segment 1 with 3-4 setae, sensillae scattered on dorsal side.

Thorax darkish brown. Episternum 1 with 913 setae. Dorsal margin of katepisternum slightly angulate. Pleural pit just at anterior part of margin.

Wing hyalinous. Length $2.5-2.7 \mathrm{~mm}$. Anal lobe well developed. c/w 0.45, R1/R 1.40-1.60. $\mathrm{bM}$ nonsetose or with a few dorsal setae, r-m, stM, M1, M2, Cu1 and Cu2 with dorsal setae. Hind margin with dorsal and ventral setae.
Legs pale brown. Front tibia with some ventral and posterodorsal spinose setae. Length of front basitarsomere/length of front tibia 0.55-0.60. Front tibia subapically with anteroapical patch of setae.

Abdomen pale brown. Hypopygium (Fig. 2A, B). Sternite 10 with 1 seta on each half.

Female. Unknown.

Discussion. I have not seen the type material but based on the descriptions with illustrations by Tuomikoski (1960) and Menzel and Mohrig $(1997,2000)$ there is no doubt about the identity of the species. Baeosciara scotica is similar to $B$. sinuata and differs from $B$. discolor and $B$. pectinata by being distinctly larger, by having the gonostylus large, strongly narrowing apicad and by having the medial part of the gonostylus without megasetae. Baeosciara scotica differs from $B$. sinuata in having only two or three megasetae on the subbasal lobe of the gonostylus instead of 15-20, in having some short stout subapical megasetae and in lacking the apical tooth. Furthermore, $B$. scotica has a subconical tegmen with strongly sclerotized parameres, whereas $B$. sinuata has the tegmen subquadrangular, without sclerotized parameres but with strongly sclerotized lateral parts of the aedeagal plate (Fig. 2; Vilkamaa \& Komonen 2001).

\section{Baeosciara sinuata (Menzel \& Mohrig) comb. n. (Fig. 2A, B)}

Trichosia (Baeosciara) sinuata Menzel \& Mohrig, 1997:38.

Material examined. Holotype male: AUSTRIA, Steiermark, Hochalm b. Leoben, subalpin, Sam.-Nr. X 1192b, leg. Franz (DEI). Other material: FINLAND, Kn, Kuhmo, 13 ơ, 20 \%, Kn, Sotkamo, 1 O’, A. Komonen leg. (MZH).

New material. FINLAND, N: Helsinki, Villinki, 7.VI.1962, O. Ranin, $10^{7}$ (MZH).

Diagnosis. Medium-sized, wing length 2.0$2.8 \mathrm{~mm}$. Thorax and abdomen brown. Wing veins $\mathrm{M}$ and $\mathrm{Cu}$ with dorsal setae, hind margin of wing with dorsal and ventral setae. Genital rod and lateral parts of tegmen strongly sclerotized. Gonostylus with apical tooth, with 15-20 slender mesial megasetae on distinct medial-subbasal lobe, and with five whiplash-like setae.

Description. See Menzel and Mohrig (1997, 2000), Vilkamaa and Komonen (2001). 
Discussion. Superficially, B. sinuata resembles those species of Dolichosciara Tuomikoski and Prosciara Frey which have a medial-subbasal group of slender megasetae on their gonostylus (see Vilkamaa \& Hippa 1996, Vilkamaa 2000). Baeosciara sinuata can easily be distinguished by having e.g. much shorter antennal flagellomeres and their necks, short maxillary palp, shorter legs with short front basitarsomere, and by having subapical anteroapical modified setae on the front tibia in a group, not in a comb as they are in the species of Prosciara and Dolichosciara, and by having whiplash-like setae and the apical tooth on the gonostylus (see Vilkamaa \& Komonen 2001). For differences between $B$. sinuata and $B$. scotica, see under the latter.

Acknowledgements. I thank Kai Heller (Kiel), Seppo Koponen (Turku), Frank Menzel (Eberswalde), Nina Laurenne (Helsinki) and Neville Winchester (Vancouver) for the material.

\section{References}

Edwards, F. W. 1925: British fungus-gnats (Diptera, Mycetophilidae). With a revised generic classification of the family. - Trans. Entomol. Soc. London 1924: 505-570.
Frey, R. 1948: Entwurf einer neuen Klassifikation der Mückenfamilie Sciaridae. II. Die nordeuropeischen Arten. - Notulae Entomologicae 27: 33-92.

Hippa, H. \& Vilkamaa, P. 1991: The genus Prosciara Frey (Diptera, Sciaridae). - Entomologica Fennica 2: 113-155.

Lengersdorf, F. 1928: Meine Sciaridenausbeute aus dem Allgäu. - Mitteilungen der Münchener Entomologischer Gesellschaft 18: 18-19.

Menzel, F. \& Mohrig, W. 1997: Revision der paläarktischen Arten von Trichosia Winnertz sensu Tuomikoski, 1960 (Diptera, Sciaridae) - Teil I. Gattung Trichosia Winnertz, 1867. - Studia Dipterologica 4: 3-40.

Menzel, F. \& Mohrig, W. 2000: Revision der paäarktischen Trauermücken (Diptera: Sciaridae). - Studia Dipterologica Suppl. 6: 1-761.

Tuomikoski, R. 1960: Zur Kenntnis der Sciariden (Dipt.) Finnlands. Zur Kenntnis der Sciariden (Dipt.) Finnlands. - Annales Zoologici Societatis Zoologicae Botanicae Fennicae 'Vanamo' 21: 1-164.

Vilkamaa, P. 2000: Phylogeny of Prosciara Frey and related genera (Diptera: Sciaridae). — Systematic Entomology 25: 47-72.

Vilkamaa, P. 2003: Phylogeny of Trichosia group of genera (Diptera: Sciaridae). - Cladistics. (In press).

Vilkamaa, P. \& Hippa, H. 1996: Review of the genus Prosciara Frey (Diptera, Sciaridae) in the Indomalayan region. - Acta Zoologica Fennica 203: 1-57.

Vilkamaa, P. \& Komonen, A. 2001: Redescription and biology of Trichosia (Baeosciara) sinuata Menzel \& Mohrig (Diptera: Sciaridae). — Entomologica Fennica 12: 46-49.

Vilkamaa, P. 2003: Cladistic analysis of Trichosia group of genera (Diptera:Sciaridae). - In: Abstracts of 21st Annual Meeting of the Willi Hennig Society: 161. 